\title{
Jeder schweigt von etwas anderem
}

Auch das Schweigen wird von einer Generation an die andere weitergegeben. Grosseltern und Eltern wissen nicht, wie sie mit ihrer Vergangenheit umgehen sollen, Enkel und Kinder passen sich an, fragen nicht zurück. Scham und Schuldgefühle der einen, Angst und Rücksichtnahme der anderen verstärken sich gegenseitig, Ohnmacht, Isolation und nachwirkende Verletzungen sind die Folgen. Wer den Weg zum Therapeuten findet, hat Glück gehabt, der Bedarf ist riesig. Der Dokumentarfilm «Jeder schweigt von etwas anderem» [1] zeigte in den Räumen der «Stasi-Unterlagen-Behörde» exemplarisch drei Familien. Eine Reiseleiterin, ein Pfarrerehepaar und einen Schriftsteller. Eltern und Kinder erzählten von Inhaftierung, Schikanen, Freikauf, Ausweisung und dem schwierigen Weg in die Normalität. Nichtkonforme Gedanken oder verbotene Schriften hatten sie in der DDR zu Staatsfeinden gemacht. Auch unausgesprochen bleibt das Vergangene gegenwärtig, und bis heute belasten die Erfahrung der Stasi-Haft, die gewaltsame Trennung von Angehörigen und die erpresste Bespitzelung durch Bekannte und Freunde die heutigen Beziehungen.

Im Anschluss an die Vorführung sprachen die Regisseure Dörte Franke und Marc Bauder mit Utz Rachowsky, einem der Protagonisten des Films. Aus dem Publikum berichtete eine Frau von den Reaktionen ihrer Töchter, mit denen sie kürzlich ihr ehemaliges Gefängnis besucht hatte. Eine andere wandte sich an ein anwesendes Mitglied der Stadtbehörde und beschwerte sich, dass Belästigungen durch ehemalige Stasi-Mitarbeiter nicht ernst genommen würden. Der Schriftsteller bestätigte ihre Erfahrungen durch eine Schilderung seiner Berliner Wohnung, die nach der ersten Filmaufführung aufgebrochen und durchsucht worden war. Es gebe ein stillschweigendes Abkommen des vereinigten deutschen Staates mit ehemaligen Stasi-Offizieren: Wir zahlen eure Pensionen, ihr verhaltet euch still. Der gegenwärtige Stadtschreiber Dresdens ortete bei den westdeutschen Behörden ein tiefgehendes Unverständnis für die Mechanismen der SED-Diktatur. Die Rechtsprechung sei einseitig positivistisch ausgerichtet und spreche mit den gleichen formaljuristischen Argumenten die Täter frei, wie sie es zuvor mit den Angeklagten der Nazi-Diktatur gemacht habe. Er argumentierte, dass wohl die Jugend Anlass zu Hoffnungen gebe, die bestehenden Strukturen aber insgeheim mit den Ideen des untergegangenen
Honecker-Staates sympathisierten. Eine früher als «antitotalitär» ausgelegte Verfassung werde heute einseitig als «antifaschistisch» interpretiert. Schliesslich seien viele Politiker und Richter früher einmal für Che, Pol Pot und Mao auf die Strasse gegangen. Eine Auffassung, die nicht einhellig geteilt wurde.

Im Winter 1989/90 wurden zahlreiche Dienststellen des Staatssicherheitsdienstes, zuletzt die Berliner Zentrale, besetzt und die Akten vor der Vernichtung bewahrt. 1991 verabschiedete der Bundestag ein Gesetz, wonach jeder und jede das Recht hat, Akten zur eigenen Person einzusehen. Bei dieser Einsicht besteht die Möglichkeit, die Decknamen der inoffiziellen Mitarbeiter entschlüsseln zu lassen. Die Klarnamen werden durch die Behörden ermittelt und mitgeteilt. Immer noch füllen in Dresden monatlich rund 500 Antragsteller ein Formular für die Akteneinsicht aus. Im Archiv an der Riesaer Strasse in Dresden-Pieschen sind rund 10000 Meter Akten des ehemaligen Ministeriums für Staatssicherheit (MfS) aufbewahrt. 3 Millionen Karteikarten und umfangreiches Fotomaterial sind zum grössten Teil für die Recherche aufbereitet. Noch 1989 wurden allein für die flächendeckende Überwachung des Bezirks Dresden 3551 hauptamtliche MfS-Mitarbeiter und 11424 inoffizielle Spitzel eingesetzt. Zahlreiche Schauwände erklären methodisch und mit Beispielen den Aufbau und die Funktionsweise des totalen Überwachungssystems. Auch das Handwerkszeug ist zu sehen: Wanzen, Miniatur- und Spezialkameras, in Gläsern konservierte Geruchsproben, Apparate zum Kopieren von Schlüsseln, zum Fälschen von Poststempeln, Einsatzpläne und abgefangene Briefe und Postkarten. Es gibt Archivführungen, Vorträge und Filmvorführungen, Projekttage, Material für Schulen und Forschungsvorhaben.

Es war nicht ganz einfach, am Anlass teilzunehmen. Die Stadt lockt Touristen mit Barockpracht und einem riesigen Angebot klassischer Vergnügungen. Es gibt kaum Hinweise auf Veranstaltungen der anderen Art, und deren Archive oder Gebäude erwähnen die Kunst- und Reiseführer nicht. Die Einheimischen leben aber ausserhalb der auferstandenen Elbkulissen, in der Neustadt, in den Plattenbauten und den zahlreichen Vororten. Auch dort ist es interessant, vielfältig und lebendig. Dort wächst die Zukunft heran.

Erhard Taverna anderem. Dokumentarfilm. Regie: Dörte Franke/Marc Bauder Deutschland; 2005. 72 Minuten. 